\title{
Analysis of massive sulphate attack to cement-treated compacted soils
}

\author{
Anna Ramon-Tarragona ${ }^{1,2^{*}}$, and Eduardo Alonso ${ }^{1}$ \\ ${ }^{1}$ Centre Internacional de Mètodes Numèrics en Enginyeria, Barcelona, Spain \\ ${ }^{2}$ Division of Geotechnical Engineering and Geosciences, Department of Civil and Environmental Engineering, Universitat Politècnica \\ de Catalunya, Barcelona, Spain
}

\begin{abstract}
The paper describes the heave experienced by two embankments providing access to a bridge located in a high-speed railway line. The compacted soil, a mixture of a low plasticity clay, sand and gravel, had a significant sulphate content $(2-2.5 \%)$. The embankments received a reinforcing treatment by mixing the soil with cement in the proximity of the bridge abutments. In addition, a grid of grouting columns provided more stiffness to the embankments. The embankments experienced a fast heaving rate (around 4 $\mathrm{mm} / \mathrm{month}$ ) in the areas improved by cement mixing. Precision extensometers indicated that heave concentrated in the upper $6-8 \mathrm{~m}$ of the embankments. The sulphate content reduced sharply to $0.25 \%$ at increasing depth. No heave was detected in these deeper zones. The swelling was found to be associated with the development of thaumasite and ettringite minerals. The presence of clay, cement and sulphates in the compacted soils and the infiltration of water from rainfall events are ideal conditions for the growth of the mentioned minerals. Long-term tests performed on compacted samples provided a good evidence of the phenomena developing in situ. A chemical modelling of the mineral changes at the soil-cement interface provided an additional insight into the development of swelling, which could last for a long time (several years). Accordingly, it was decided to underpin the railway track and to excavate the upper active volume of the embankments. This solution went in parallel with train service, which was never interrupted.
\end{abstract}

\section{Introduction}

Sulphate attack explains the development of surface heave in cement-and lime-stabilized soils. The attack also results in a reduction of soil strength and has affected a number of road bases and sub-bases ([1-4]). The soil stabilization treatment usually encompasses thin layers of soil; however, massive sulphate attack can also occur when the treatment concerns larger soil masses. This is the case of two railway embankments, Pallaressos embankments, built in Spain and affected by sustained damage ([5]).

The paper describes the embankments design and performance, the geotechnical investigation carried out, the interpretation of observed expansions and damage, two numerical simulations of the chemical processes and its mechanical effects taking place within the embankments and the remedial measures conducted.

\section{Pallaressos embankments features}

Pallaressos embankments belong to the high-speed railway connection between Madrid and Barcelona and were built in the province of Tarragona, Spain, in 2004. The embankments give access to a bridge $196 \mathrm{~m}$ long, Pallaressos bridge, and have a maximum height of $18 \mathrm{~m}$ in the proximity of the bridge abutments. Structural details of Pallaressos Bridge are described in [5].

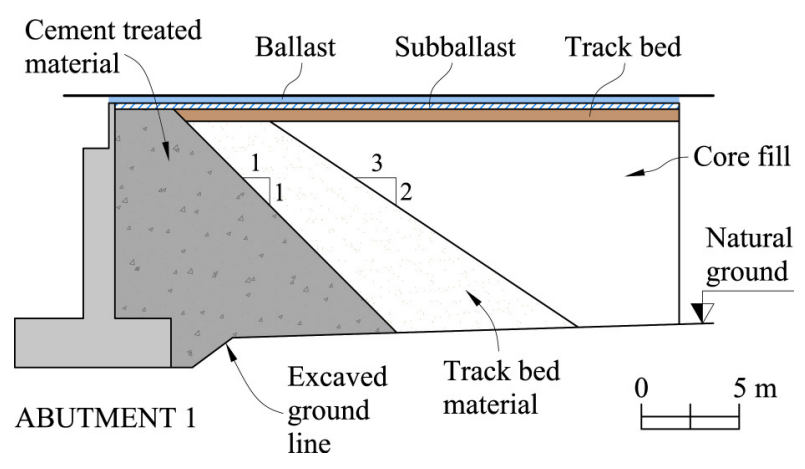

Fig 1. Design of the embankments and transition wedges

A compacted sulphated claystone constitutes the core fill of the embankment. The material used originated from the excavation in a nearby Miocene natural formation that consists in a sequence of claystone levels and sandstones poorly cemented containing some proportion of gypsum veins and interbedded limestone layers. This is the same geologic formation involved in the extreme expansive problems that suffered Lilla tunnel ([6-7]) and Pont de Candí Bridge ([8]) due to gypsum crystal growth. Figure 1 shows the internal design of the embankments in longitudinal section. A

Corresponding author: anna.ramon@upc.edu 
transition wedge placed in the vicinity of the abutment structures in both embankments provides a progressive variation of stiffness when trains approach the rigid structure from the embankment. Cement treated soil was used to build both wedges.

Periodical track levelling monitoring carried out by railway administration identified the development of vertical displacements near the abutments, a short time after the end of the construction of embankments. Rail levelling recorded maximum heave rates of 4.0-4.5 $\mathrm{mm} / \mathrm{month}$ with no signs of reduction in heave rate.

Afterwards, each embankment was reinforced by means of a grid of $1.5 \mathrm{~m}$ jet-grouting columns. The treatment covered a width of $14 \mathrm{~m}$ at the central part of the embankment along $30 \mathrm{~m}$ from the position of the abutment. The columns length and density were higher in the vicinity of the abutments. The reinforcement derived from the appreciated weakness of the embankment material and a poor wedge design observed from boreholes performed through embankments. However, heave did not stop after the jet-grouting reinforcement.
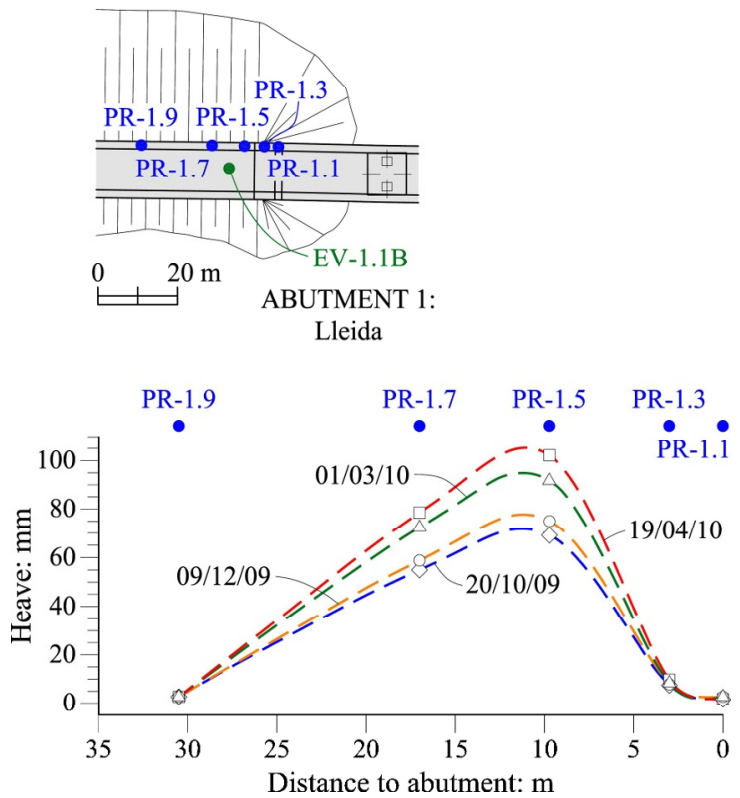

Fig 2. Distribution of surface heave along the embankment length. Initial topographic levelling measurement 26 May 2008

\section{Field investigations}

A survey of the surface of the embankments by means of topographic marks identified the development of horizontal and vertical surface movements in both embankments. The behaviour recorded in both embankments was similar. Significant surface horizontal displacements up to $150 \mathrm{~mm}$ developed in the transverse direction during the first 18 months of monitoring. The records showed an accumulated heave of $59 \mathrm{~mm}$ in the same period. Surface monitoring also measured horizontal movements in the longitudinal direction of the embankments. However, the values of displacements were substantially lower. Topographic marks installed along the first $10 \mathrm{~m}$ from the abutment measured maximum displacements up to $22 \mathrm{~mm}$ towards the abutment structure. The confinement, applied by the abutment and the bridge structure on one side, and, by the rest of the embankment on the opposite side, explains the smaller displacements observed in the longitudinal direction.

Figure 2 shows the distribution of the vertical surface displacements measured along the distance from the abutment position in different times. The distribution of the transversal surface movements has a similar shape. The maximum displacements concentrate at 10-13 $\mathrm{m}$ far from the abutment position and no significant movement is detected at distances to the abutment greater than 30 $\mathrm{m}$. Topographic marks were also installed in natural ground surface and no movements were recorded.

The heave rate was not constant in time. The estimation of average heave rate obtained from different measurement procedures shows that heave rate increased from values ranging $2-4 \mathrm{~mm} / \mathrm{month}$ to values up to 7.5 $\mathrm{mm} / \mathrm{month}$ in 3 years of monitoring. The rainfall events play a role in the evolution of heave. The development of vertical displacements accelerates immediately after significant rainfall events (Figure 3).

Inclinometer records along boreholes showed that horizontal displacements were developing in depth. Systematically, horizontal movements decreased gradually along the first $8-10 \mathrm{~m}$ of borings. No significant horizontal displacements were recorded at positions deeper than 13-14 m. Continuous extensometers (sliding micrometres; [9]) installed in boreholes investigated the vertical deformations of the embankments. The extensometers were installed at different distances from the abutments reaching the natural substratum under the embankments. A typical record of vertical displacement shows the concentration of swelling deformations at the upper $8-10 \mathrm{~m}$ over time and smaller compressive strains at the deeper part of the embankments (Figure 4). The expanding level did not progress downward in time.

Micrometres installed $40 \mathrm{~m}$ far from the abutment measured only small compression. The integral of strains recorded along the length of the extensometer was consistent with the surface heave measured in topographic levelling of the embankment surface. In addition, a continuous extensometer installed in natural ground, measured no straining and indicated that the only source of movements was the deformation of the embankments in this case. All the sliding micrometres installed showed that the natural substratum under the embankments was unstrained.

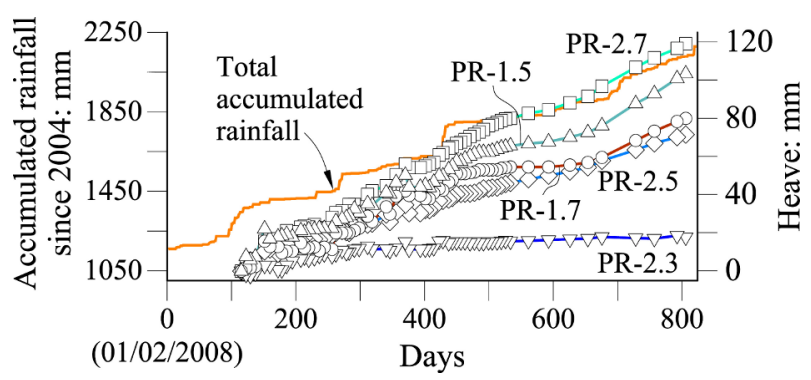

Fig 3. Evolution of surface vertical displacements at both embankments and total accumulated rainfall recorded by the Servei Meteorològic de Catalunya near the bridge. 


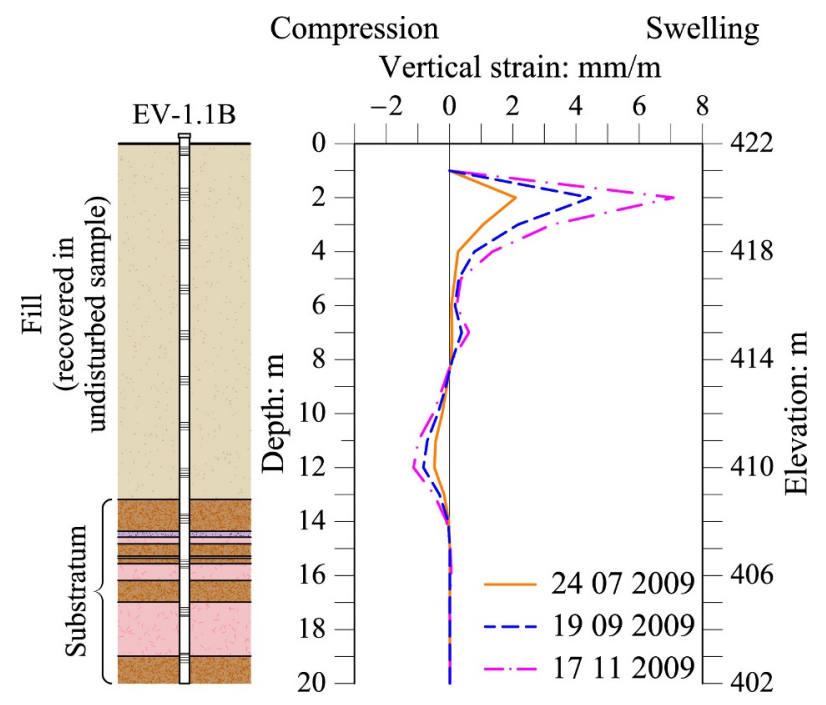

Fig 4. Vertical displacements measured in a sliding micrometre located $7 \mathrm{~m}$ far from abutment. Initial measurement 25/5/2009.

The three-dimensional internal swelling of the embankments implies that it may result in the application of high horizontal loads against the abutments. If they exist, these loads may be transmitted symmetrically against the bridge. Actually, an inspection of the bridge structure showed the presence of fissures and spalling damage at the contact between the abutment and bridge structural elements, a displacement of the abutment structure towards the bridge and severe damage in the communications and drainage (Figure 5). In addition, it was observed a pattern of bending-induced cracking on the lower part of the pillars, in agreement with the presence of opposing forces on both sides of the bridge.

The reduced longitudinal deformation also pointed out to the possible development of strong passive stresses at the upper level of the embankment. An analysis of this effect is described below.

\section{Laboratory investigations}

Continuous cores and undisturbed samples were recovered from boreholes drilled for the installation of monitoring instrument. Samples from different depths were tested. Figure 6 describes the heterogeneous distribution of some identification properties in depth. The fine fraction is a low-plasticity clay.

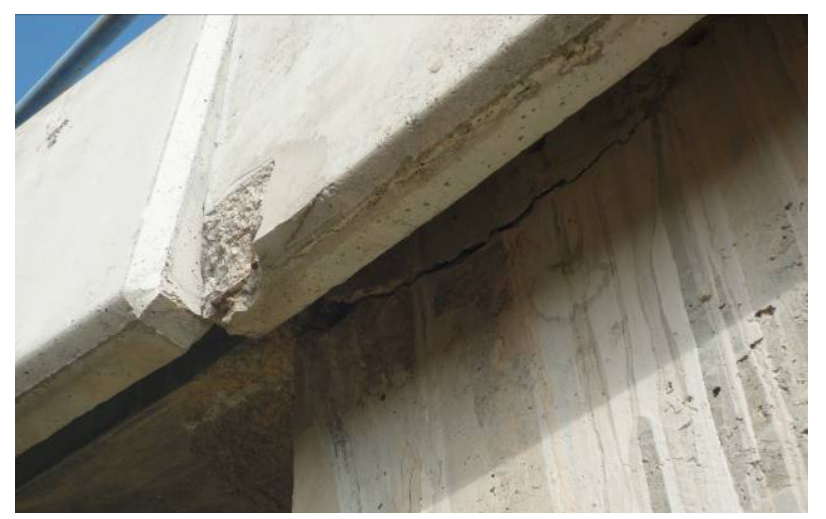

Fig 5. Spalling and fissures observed near abutments

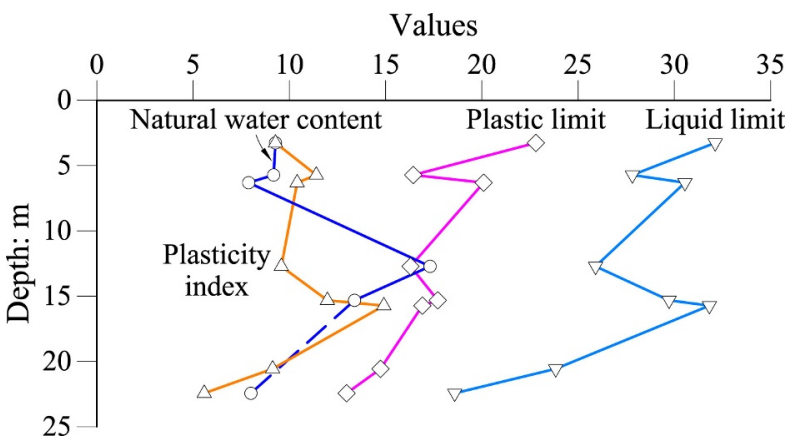

Fig 6. Index properties determined in samples taken in a boring drilled through one embankment.

Figure 7 shows the exposed surface of a cut through the upper part of the embankment. The excavated pathway on the embankment side was made to allow the access of drilling machines for the installation of measuring instruments. The cut in the photo displays the aspect of compacted fill with abundant presence of gravels and small boulders. Grain-size distribution test results show that the ranges for each fraction are wide (Table 1). Also, some boulders with sizes in excess of $100 \mathrm{~mm}$ were scattered inside the fill.

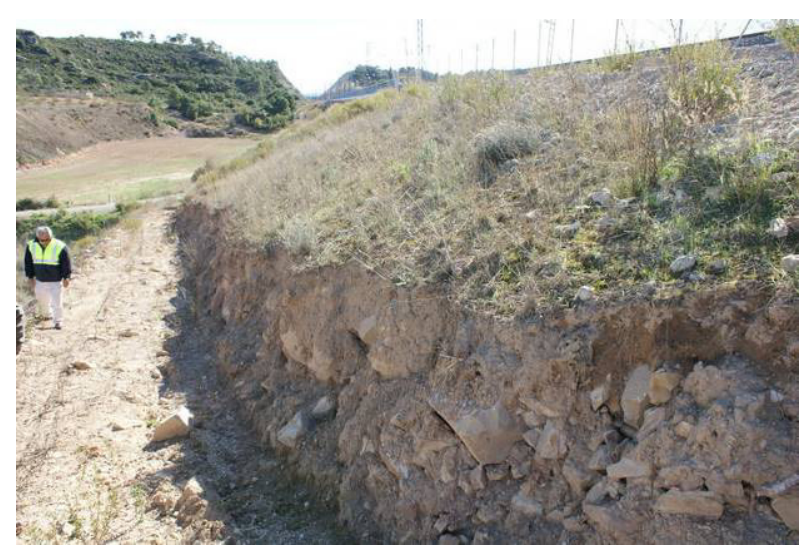

Fig 7. Detail of embankment material from an open cut.

Table 1. Grain size distribution of compacted soil

\begin{tabular}{|c|c|}
\hline Grain size & Average value and range \\
\hline Gravel & $62.1 \%-18.6 \%(35 \%)$ \\
\hline Sand & $35.1 \%-10.5 \%(21 \%)$ \\
\hline Fines & $69.3 \%-7 \%(35 \%)$ \\
\hline Boulders (>100 mm) & Scattered \\
\hline
\end{tabular}

A relevant characteristic of the test results was the distribution along depth of soluble sulphates in the soil (Figure 8 ). The samples recovered from the upper 8 meters showed values ranging from 2.0 to $2.5 \%$. The sulphate content decreased to less than $0.5 \%$ at deeper positions. This was probably a result of the presence of two different source areas for the material used to build the embankments. 


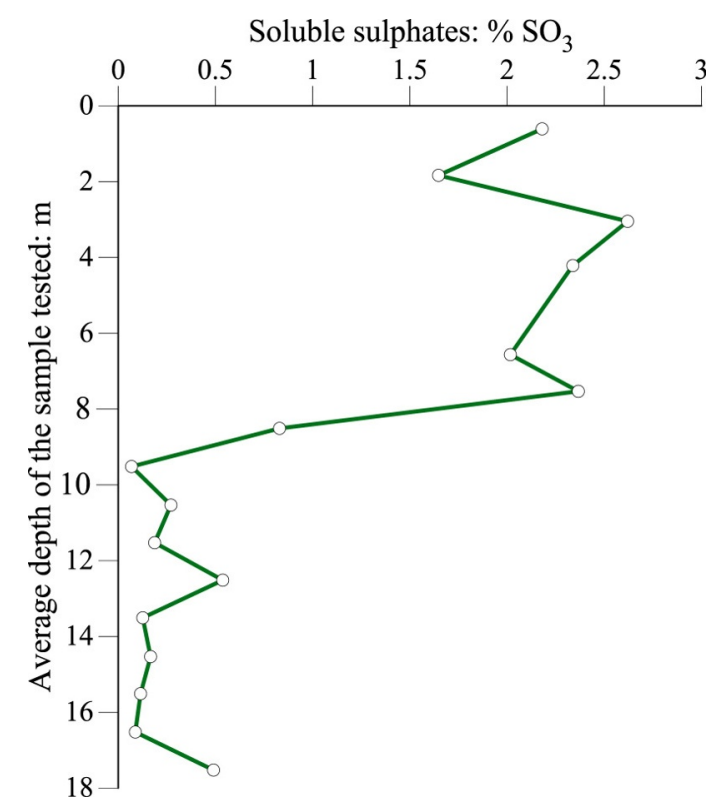

Fig 8. Vertical profile of soluble sulphate content found in samples recovered in a borehole.

Free swelling tests carried out on compacted samples approximated the conditions in the embankments. The compaction to standard Proctor energy of the homogenized soil recovered along $1.20 \mathrm{~m}$ boring lengths provided four representative samples of the upper 5 meters of the embankments. The unloaded samples, 120 $\mathrm{mm}$ in diameter and $160 \mathrm{~mm}$ height, were partially submerged in water and were tested under a constant temperature of $8{ }^{\circ} \mathrm{C}$ for more than a year (Figure 9). Figure 10 shows the evolution of vertical strains in the tested samples. All the samples developed a very relevant long-term swelling which is not expected in a low-plasticity soil compacted at a standard proctor density. Swelling evolved over time with no signs of levelling off.

The analysis of the testing sample exhibiting higher expansion (originated from $1.2-2.4 \mathrm{~m}$ deep) by means of X-ray diffraction and scanning electron microscopy (SEM) observations identified ettringite and thaumasite crystals. The role of these two minerals in the swelling phenomena will be discussed in the next section.

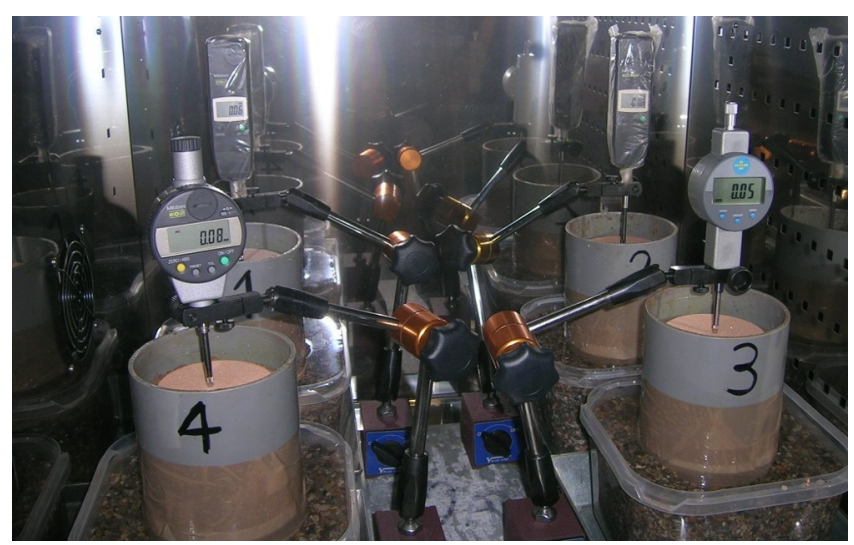

Fig 9. Free swelling tests on compacted samples

\section{Interpretation and swelling scenario}

Field measurements provided a clear position of an "active expanding volume" within the upper 8-10 meters of each embankment. The observations of the embankment surface distortions and structural damage to abutment structures suggest that they are a consequence of a three-dimensional internal swelling of the embankment.

A detailed analysis on the material recovered from different locations in the embankments enlightened the interpretation of the swelling phenomena. X-ray diffraction analysis, and SEM-EDS and optical microscope observations identified always the presence of ettringite and thaumasite minerals in samples exhibiting poorly cemented soil-cement mixtures or pure cement grout, which had a wet to muddy consistency and a whitish colour. Figure 11 is a characteristic pattern of an area of a sample occupied by thaumasite. Calcite, gypsum, quartz, dolomite, illite and kaolinite composed the clay matrix.

Damage in road bases and sub-bases related to sulphate attack is well known when the soil has some proportion of gypsum or the treated soil is exposed to sulphated water. Very low threshold values $(0.3 \%)$ have been identified to be enough to trigger the attack [3]. The works of [2] and [4] collect some experiences in cementand lime- treated soils.

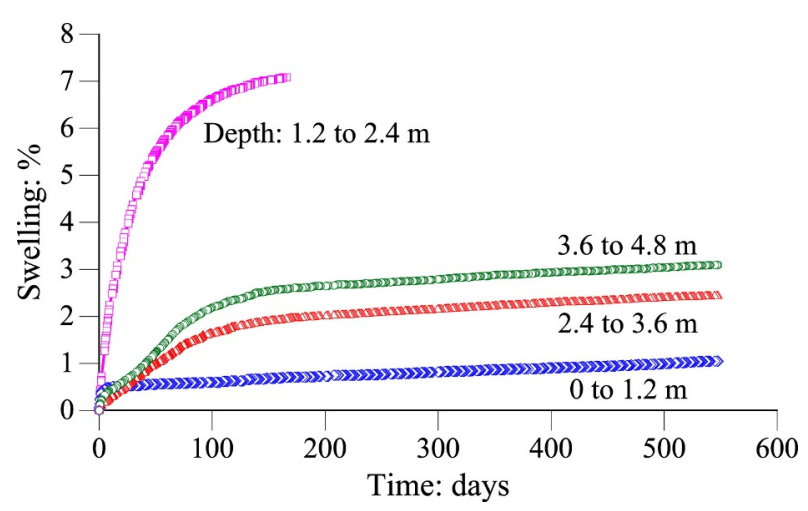

Fig 10. Long term swelling tests on compacted samples.

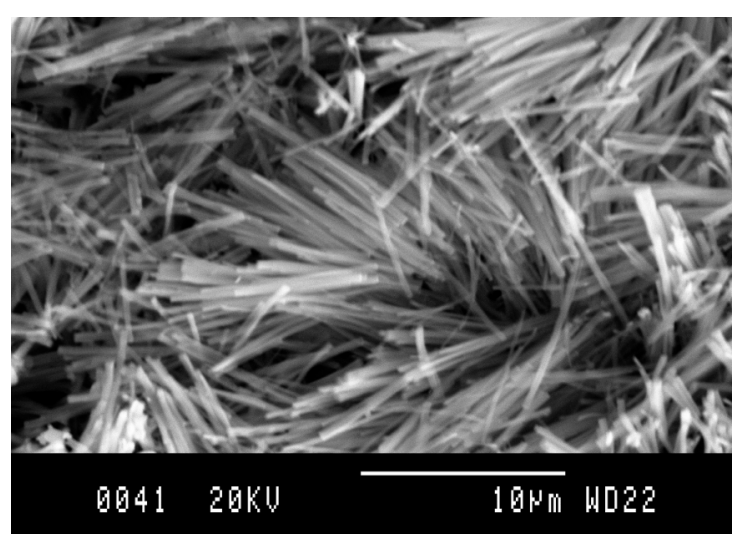

Fig 11. Detail of thaumasite crystals found in a tested sample recovered from the embankments 
Sulphate attack of a treated soil leads to the development of ettringite $\left(\mathrm{Ca}_{6}\left[\mathrm{Al}(\mathrm{OH})_{6}\right]_{2}\left(\mathrm{SO}_{4}\right)_{3} \cdot 26 \mathrm{H}_{2} \mathrm{O}\right)$. This mineral crystallises in bundles of elongated filaments. The development of ettringite implies a destruction of the strength of the cement paste and a substantial swelling. Another mineral, thaumasite $\left(\mathrm{Ca}_{6}\left[\mathrm{Si}(\mathrm{OH})_{6}\right]_{2}\left(\mathrm{CO}_{3}\right)_{2}\left(\mathrm{SO}_{4}\right)_{2} \cdot 24 \mathrm{H}_{2} \mathrm{O}\right)$ develops also as a consequence of sulphate attack. The proportion of water molecules in their crystalline structure is also very high.

[10] described the development of both minerals in lime-stabilized soils following a complex process. The process is triggered by the highly basic environment generated after the hydration of lime. High $\mathrm{pH}$ is capable of dissolving, firstly, the clay minerals, releasing $\mathrm{Al}$ and $\mathrm{Si}$ ions, and, secondly, sulphate minerals, which provide a source of $\mathrm{Ca}^{2+}$ and $\mathrm{SO}_{4}^{2-}$. Ettringite precipitates when aluminium released from clays, calcium from cement or lime and sulphates combine with water molecules. Carbonic acid, present in the pore water and the dissolution of calcite leads to precipitation of thaumasite, once ettringite is present. Crystals develop in the pore solution.

The embankment design and the analysis of the material recovered suggested that the mechanism of expansion due to the precipitation of ettringite and thaumasite crystals can develop within the upper part of the compacted soil mass of the embankments. The proportions of sulphate contents are high along the upper layers of the embankments, where expansions concentrate and cement is also present both at the transition wedges and in the jet-grouting treatment. Moreover, the availability of water from rainfall and the availability of clay minerals guarantee the possibility for the formation of thaumasite and ettringite, essentially unlimited in the embankments.

\section{Modelling chemical processes and embankment swelling}

A simulation of the processes taking place at the soil/cement interface provided an improved understanding of sulphate attack and an evaluation of the possibility of ettringite "natural" occurrence within Pallaressos embankments. The program RETRASO ([11]) was used to analyse the simple one-dimensional problem represented in Figure 12(a): the interaction of two porous materials, the compacted soil and a cement grout, through a common interface. RETRASO allows solving the coupled hydraulic transport processes and the chemical reactions. The analysis involved the calculation of the distribution in space (at both sides of the interface) and the evolution over time of several chemical constituents, for instance, the dissolved or precipitated amounts of calcite, dolomite, kaolinite, portlandite, gypsum and ettringite, and also the $\mathrm{pH}$ of the soil and cement pore water, a key piece of information to explain the sulphate attack. Figure 12 gives some results for a calculation period of 5 years.

The $\mathrm{pH}$ maintains a high value on the cement side of the interface over time, while, a plume of high $\mathrm{pH}$ values migrates progressively towards the soil (Figure 12(b)).
At the same time kaolinite is being progressively dissolved in the soil, starting at the interface (Figure 12(c). The consequence is the release of $\mathrm{Al}$ ions, necessary for ettringite precipitation. The concentration of sulphate increases at the interface and in the immediate vicinity, which induces the precipitation of ettringite. Therefore, in parallel, an ettringite front advances in the cement medium (Figure 12(d)). In 5 years, the simulation calculates a deep penetration of 1.5 $\mathrm{m}$.

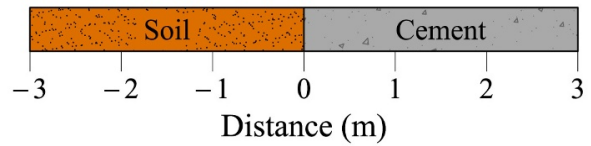

(a)

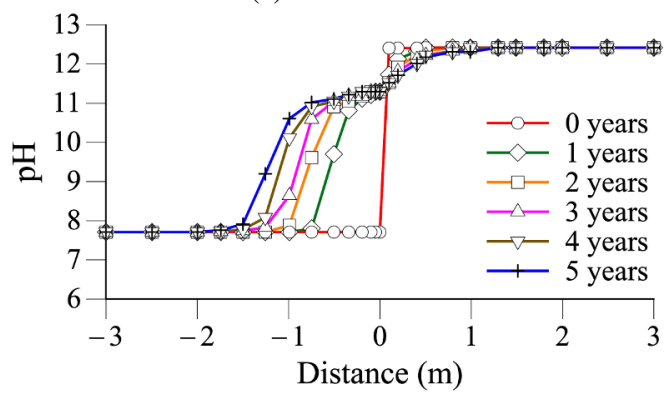

(b)

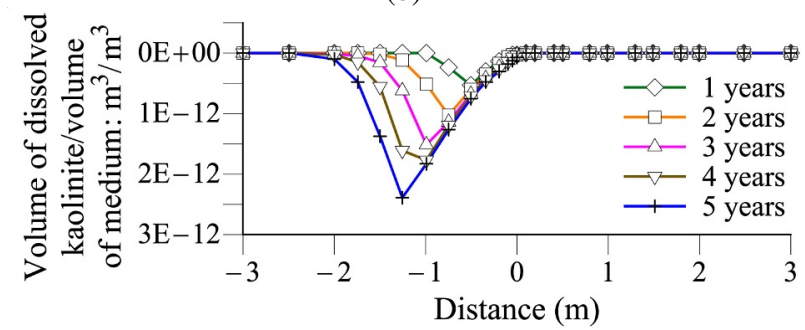

(c)

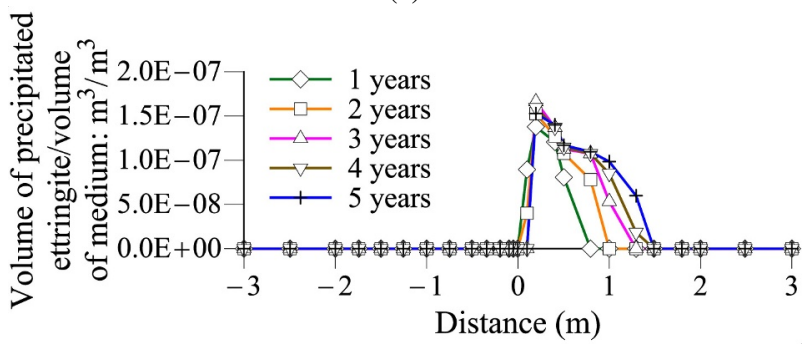

(d)

Fig 12. Analysis of soil-cement reactions with the program RETRASO. (a) Geometry of the problem; Evolution and distribution of: (b) pH; (c) volumes of kaolinite and (d) volume of ettringite.

The real problem is exceedingly complex compared with the chemical analysis performed. For example, the pore water was probably under significant suction values for most of the time. Therefore, no attempt was made to couple the chemical calculations with the observed heave. In contrast, a finite element model of embankment swelling approached the measured swelling strains and surface heave to study their effect on the bridge. The plane-strain analysis performed also estimated the state of stress on the embankments.

The sliding micrometre records and the measured surface heave guided the definition of imposed volumetric strains distributed in some sectors of volume 
at the upper part of the geometry of the embankment. Figure 13 shows the matching between measured and calculated heave after expansions. The model calculates a dangerous state of passive stresses on the upper 8-10 m of the embankment after swelling strains development. In addition, the calculation estimated a total force of 2.32MN/m against the bridge abutment.

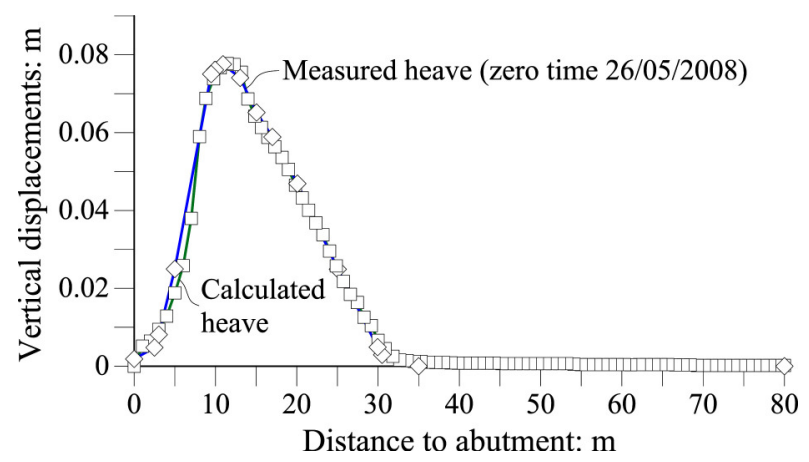

Fig 13. Comparison between measured and calculated heave.

\section{Comforting solutions}

Although the abundant presence of thaumasite indicated an advanced state of sulphate attack, expansions recorded in both embankments suggested that swelling phenomena and, therefore, the development of both the passive state of stresses and forces against the bridge would continue over time.

The excavation of the upper 6 meters of the embankment along the stretch affected by sulphate attack defined the comforting solutions carried out. The remedial solution also included the underpinning of rail tracks by a structure founded on bored piles on both sides of the embankment. Figure 14 sketches the design of the remedial measures built. The operation of the railway was maintained during the execution of the remedial works.

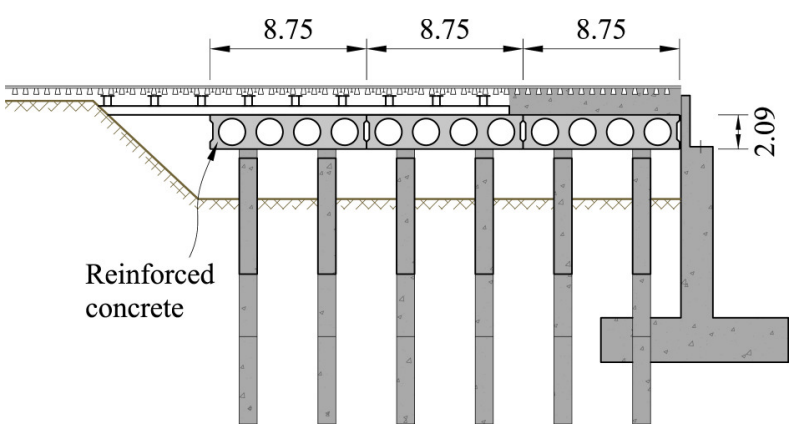

Fig 14. Longitudinal section along one embankment showing the design of the remedial solution built.

\section{Conclusions}

The records of sliding micrometres and the results of topographic investigations performed in the site of Pallaressos embankments showed that a volumetric expansion affected both embankments. Swelling resulted in the development of a passive state of stress, menacing the rail tracks. Expansions also derived in high forces applied against the abutment wall that were damaging the bridge. An active massive sulphate attack to the compacted embankments explained the observed swelling. The contents of sulphate at the upper $8 \mathrm{~m}$ of the compacted material $(2.5 \%)$ joined with the cement treatments applied at transition wedges set a dangerous scenario for sulphate attack occurrence. The unlimited availability of the other necessary chemical components (sulphates from the soil, alumina and silicates released from clay minerals, calcium from cement components and gypsum and water) suggested that the formation of ettringite and thaumasite and, therefore, deformations in the embankments would proceed for a long time if no remedial measures were carried out.

\section{Acknowledgements}

The authors acknowledge the technical and economic support provided by the Spanish Railway Agency, ADIF. Thanks are also given to Dr M. Saaltink for his help on the chemical modelling and to Professor E. Vázquez, Dr. M. Barrera and Dr. E. Tauler of the Universitat Politècnica de Catalunya and the Universitat de Barcelona for their contribution in the mineralogical identification. IIC installed the field instrumentation and provided the auscultation data included in the paper.

\section{References}

1. P.T. Sherwood, HRB Bull., 353, 98-107 (1962)

2. J.K. Mitchell, \& D. Dermatas, ASTM Special Technical Publication, 1135, 41-64 (1992)

3. A.J. Puppala, E. Wattanasanticharoen \& K. Punthutaecha, Ground Improvement, 7, No.1, 25-35 (2003)

4. G. Rajasekaran, Ocean Engineering, 32, 1133-1159 (2005)

5. E. E Alonso \& A. Ramon, Géotechnique 63(10): 857 - 870 (2013)

6. E.E. Alonso, I.R. Berdugo, \& A. Ramon, Géotechnique 63 (7), 584 - 612 (2013)

7. A. Ramon, E. Alonso \& S. Olivella, Géotechnique 67(11): 968 - 982 (2017)

8. E. E. Alonso \& A. Ramon, Géotechnique 63 (9), 707-719 (2013)

9. K. Kovári \& C. Amstad, Géotechnique, 32, No. 4, 402-406 (1982)

10. A. M. O. Mohamed, Engineering Geology 57, 193203 (2000)

11. M., I. Saaltink, C. Ayora \& S. Olivella, User's guide for RetrasoCodeBright. (Dept. of Geotechnical Engineering and Geo-Sciences, UPC. Institute of Earth Sciences Jaume Almera, CSIC, Barcelona. 111 pp, 2005) 